\title{
The cluster approach in the economic and innovative development of mining region (on the example of the Kemerovo region)
}

\author{
Evgeniya Shavina ${ }^{1, *}$, and Viktor Prokofev ${ }^{2}$ \\ ${ }^{1}$ Plekhanov Russian University of Economics, Academic Department of Political Economy and \\ History of Economic Science, 117997, Moscow, 36 Stremyanny lane, Russia \\ ${ }^{2}$ National university of oil and gas «Gubkin University», Department of oil and gas industry, Faculty \\ of Economics and Management, 119991, Moscow, 65 Leninsky prospekt, Russia
}

\begin{abstract}
The transition to sustainable development and the new industrial transformation of resource-dependent countries are closely intertwined. The cluster approach is an effective means of realizing industrial potential in the context of innovative development. Clusters' innovation potential is influenced by the network synergies that result from active regional policies. The article considers the mechanism of supporting regional clusters by creating and maintaining the viability of regional innovative systems that enhance the effect of the creation of agglomerations, and allow industrial clusters to move to innovative clusters. The latter are the highest form of enterprise development, as the connection with territorial advantages is lost. In addition, the article raises the question of the feasibility of diversifying regional economies by creating tourist clusters and promoting their brands. This type allows economies to be more resilient to crises, to increase attention to environmental issues, and to further increase the revenue part of budgets.
\end{abstract}

\section{Introduction}

The issues of stimulating economic growth are important in modern economic policy [1,2]. The difference between regions in terms of economic development, cultural, religious, social and other non-economic features, limited measures of influence of the federal authorities allows us to talk about the expediency of the active role of regional authorities. The regional authorities, along with traditional and forward-looking planning, should consider and consistently implement measures to develop the region. Modern cluster theory and the peculiarities of regional innovative clusters as complex adaptive systems are the theoretical basis for making management decisions.

Let us turn to the experience of the Kemerovo region, as a region in which cluster initiatives have found support and are successfully functioning.

The Kemerovo region is located in the Siberian Federal District in eastern Russia. Kuznetsky Basin Coal Industrial Cluster (technology center), agro-industrial cluster,

\footnotetext{
* Corresponding author: evgeniyashavina@gmail.com
} 
biomedical technology cluster, tourist and recreational cluster were created to stimulate economic development. The region is home to the Siberian branch of the Russian Academy of Sciences, 4 universities, 8 specialized institutes. The regional authorities are trying to form a cluster of arts to stimulate and optimize the activities of non-profit organizations.

The region's economy is based on mining (coal), manufacturing, and metallurgy. The region's manufacturing industry consumes 165.5 thousand. KWh and on this indicator is second only to The Krasnoyarsk Region, the Republic of Khakasia, Karelia and Murmansk region. This shows the possibility of reducing the electric intensity of production, including the transition to the principles of careful production.

The level of urbanization is $86 \%$, which is higher than the average Russian level $(74.6 \%)$ and is of high importance among other regions (second only to cities of federal importance, Murmansk and Magadan region) [3]. A high proportion of the urban population creates the prerequisites for the development of technological centers, since employees are provided with cultural and social facilities, there is no need to think about satisfying basic needs and you can concentrate on the development of computer programs, new technical means (sensors, sensors, other measuring instruments, including within industry 4.0).

At that time there is a risk of food security and the risks associated with mass congestion are exacerbated, example, the spread of Covid-19. As for food security, the Kemerovo region borders on historically established agricultural regions: the Altai region, the Altai Republic, partly the Novosibirsk region. At the same time, it is important to have a portfolio of promising agricultural projects, including clusters, to ensure food security. Thus, companies of the South Kuzbass cluster, where large steel mills are concentrated, can interact with agroindustrial companies to provide the economy with machinery, materials for warehouses and flow lines in food processing plants.

Gross regional product per capita 462.5 thousand rub. less than the average Russian 578.7 thousand. Rub. Its annual growth is observed, which was made possible by active economic policy in the region, including in the area of clusters.

\section{Materials and methods}

Clusters are a model of industrial organization in many countries as they transition to an innovative growth model. Evolutionary theory, the theory of spatial development, the theory of technological change and systemic innovation, and Porter's theory of competitiveness have made a significant contribution to cluster theory. Clusters were considered both as a form of industrial agglomerations, and as innovative ecosystems, and as a special class of economic projects (cluster initiatives) $[1,2,4,5]$.

The study of the role of clusters consists in geographical and functional fragmentation of production, in integrating local exporters into global value chains, and in bridging communication gaps and developing cooperation between economic agents. Clusters are central to different types of business networks, making them key building blocks of the modern industrial landscape and innovation environment (fig.1,2). 


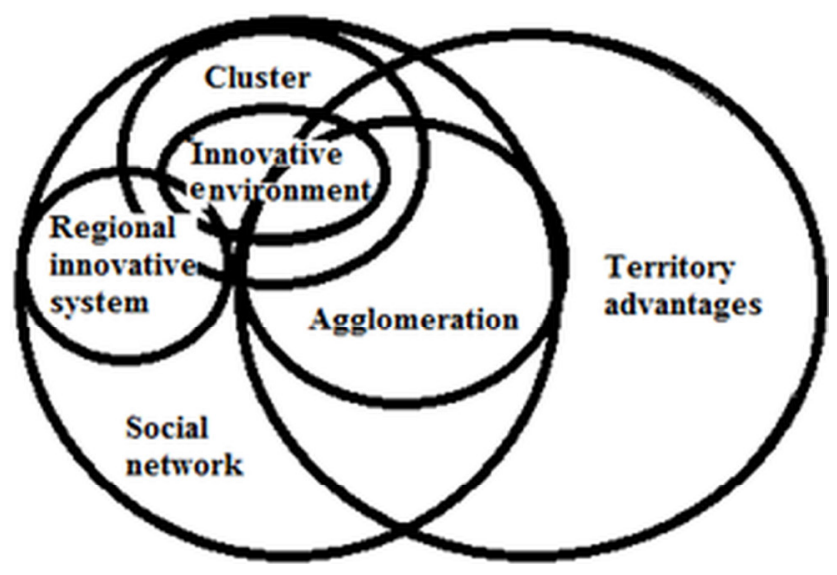

Fig. 1. Place of innovative environment in terms of space development. Source: composed by the authors.

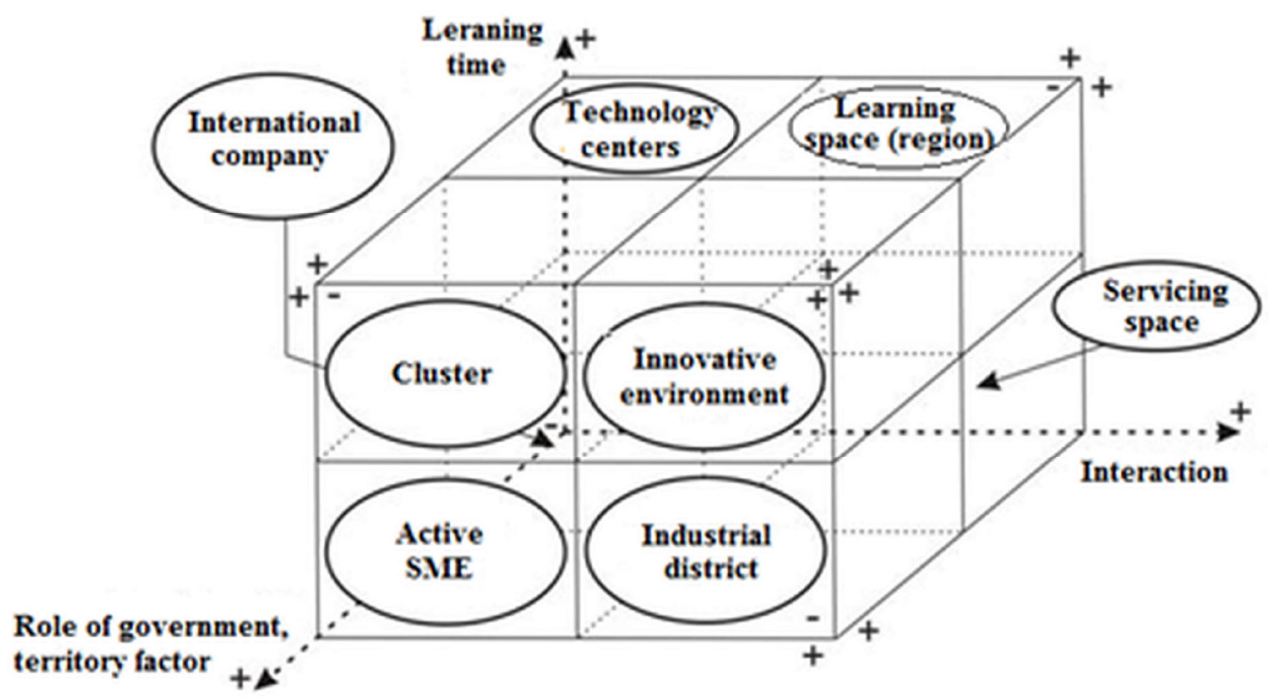

Fig. 2. Forms of development. Source: composed by the authors.

Human relations are at the heart of economic processes. The totality of relationships between all actors in a particular environment is called social networks (SNs). They make industrial clusters successful. This is the conclusion made by Turkish scientists when considering the impact of networks on engineering clusters [5,6]. Innovation activity is constrained by the lack of knowledge sharing that does not occur in clusters in which employee interactions are nominal. Clusters that do not establish social media channels, i.e. sustainable human interaction on the formation, exchange and use of knowledge, cannot develop and are gradually disintegrating [6].

However, a Taiwanese scientist Cheng, considering industrial clusters, argued that the knowledge gained through $\mathrm{R} \& \mathrm{D}$ and testing or experience is more significant than the knowledge gained through the network [7]. A. Isaksen, F.T'dtling, M.Trippl declared that social networks have limited influence on innovative processes, as different metrics should be used to detect the role of networks in cluster innovation [8]. 
Social networks in the production process, together with the means and materials of production form Local Production Systems (LPS). These are long-established companies that have shown their resilience in times of crisis. In most cases, they are city-forming, they are occupied by the vast majority of the population. In the Kemerovo region are the North Kuzbass Coal Company, SDS Coal Holding Company, Kuzbassrazrezugol Coal Company, which produces and enriches coal. Some of the coal is then exported, and some are used for metal distribution (companies: EVRAZ United West Siberian Metallurgical Plant, Kaltan Metal Works, Jurgin and Angers Machine Plants). These companies are "gazelles" in the terminology of Birch [9], i.e. companies exhibiting long-term and fast growth.

The concept of «a gazelle firm» was introduced by David Birch in the 1980s. It was found that the majority of both large ("elephants", according to Birch) and small ("mice") companies grow slowly and make a minimal contribution to employment growth and GDP growth $[9,10]$. There is, however, a small group of firms that combines high growth dynamism and sustainability. D. Birch gave them the later generally accepted name "gazelles", emphasizing the similarity of this type of firm with the animal. According to Birch's algorithm, companies are classified as "gazelles" that show revenue growth of $20 \%$ or higher each year for at least 5 consecutive years.

In 2019, the ratio of firms of different categories corresponded to the russian-russian indicators, at the same time the number of gas companies in the Kemerovo region increased by 7.9 times, while in Russia as a whole the growth was 3.6 times (fig.3).

"Gazelles" are agents of borrowing, adapting and developing technologies. At the same time, the number of "gazelles" in our country is significantly higher, and the relative contribution to economic growth is lower than in the West; among large and medium-sized firms, they alone provide long-term employment growth. This fact shows that companies have efficiency reserves, but do not use them for various reasons, one of these is an insufficiently coordinated policy of interaction with other companies.

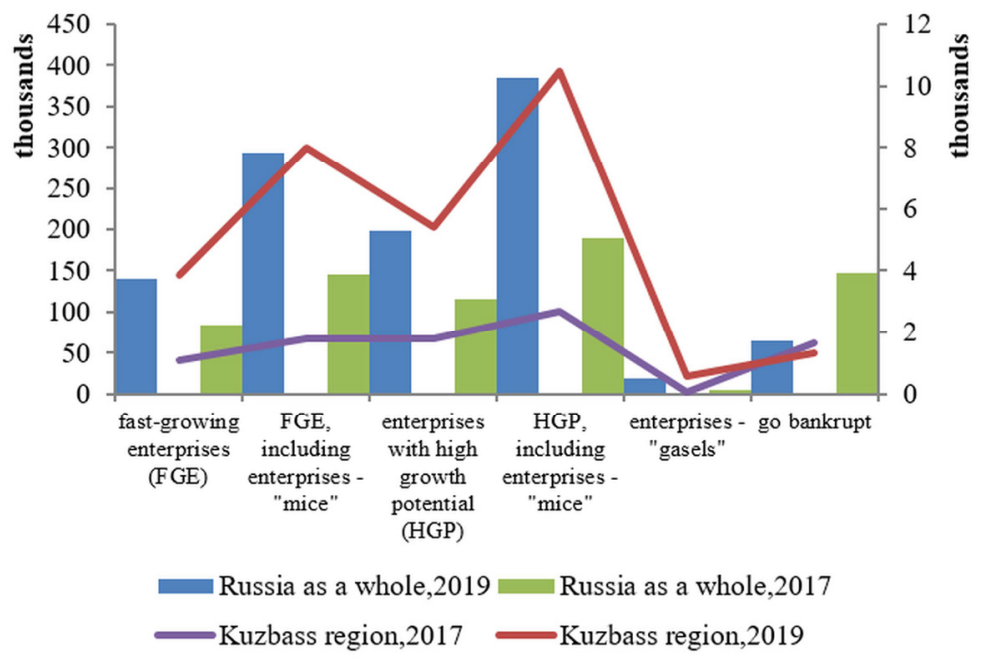

Fig. 3. Numbers of enterprises per category by revenue growth in Russia and Kuzbass, 2017-2019: composed by the authors on materials [3].

A system that brings together different firms and organizations that participate in the processes of interactive learning and the generation of new knowledge are part of the regional institutional environment (RSI). Structurally, RSI comprises two subsystems: technology and economics (regional clusters of business entities) and institutions (innovative and purposefully created infrastructure) [11]. 
Hosts are the core of RSI because they contribute to creating an innovative environment through innovative policies, strengthening in-organizational innovation partnerships, supporting infrastructure, increasing institutional knowledge density, and increasing the number of knowledge generators.

At the same time, an important part of RSI are institutional structures, the formation and development of which, allows to form the conditions for the emergence of innovative systems. Innovative systems can appear in any region, but their subsystems can function very differently. Agglomerations are usually formed from numerous support infrastructure organizations. The peripheries (remote from regional centers) have low institutional density (few actors innovate), which often leads to dependence on external networks [12].

Clusters bring together companies from different industries associated with the creation of the finished product. An alternative to this way of industrial organization service space. The service space is a space of social relations of actors companies, which operate not only in accordance with their role and status (consumer - executor of services), but also regulated by the rules, rules existing in the service, as well as the customs of service (international, country, regional). The implementation of service relationships is not limited to customer service, but space actors are media and other roles. Space actors form their own badge of distinction, which is due to the special quality of service, not tied to a particular territory, but dependent on the needs of the consumer [13]. These spaces are self-sufficient, at the same time clusters cannot exist without them. The advantageous location of the Kemerovo region gives it the opportunity to engage in cluster policy, as neighboring regions (Altai region, Krasnoyarsk region), according to this characteristic are service spaces.

\section{Results and Discussion}

In the regional economic space, clusters are formed by industries with the greatest competitive potential. The industrial cluster is a closely connected set of enterprises of different scales and levels, institutions and support organizations that unite in a particular region and cooperate with each other through their network through a division of labour.

Sustainable cluster development is possible with the intellectual potential of social networks, and the transition to an innovative economy is achieved by the accumulation and improvement of knowledge. The link in this process is higher education and research institutions. The role of academic institutions is to train relevant professionals, to improve the skills of staff, and to conduct research and market-oriented research.

At the same time, studies conducted by Evans and Sawyer [14] show that small and medium-sized enterprises (SME) are a key cohort interested in innovation. SMe's face a number of problems, mainly in "mining areas." These include difficulties in attracting and retaining staff due to lack of social services and unaffordable housing, lack of skilled personnel and wage competition [15]. Thus, while SMe is often encouraged to "capitalize the wealth of the mining boom", for many regional enterprises, innovative practices in attracting staff, complex product development and on-site customer service are not available for the reasons outlined above [14].

In Russia, and in particular in the Kemerovo region, the innovation activity of large enterprises significantly exceeds the same rate of medium and small enterprises. The main reasons for the existence of this trend is a higher level of development of the technological base of large enterprises and the corresponding professional and qualification capacity of personnel in all areas, more financial resources available to a large enterprise. They are the ones who have and create new subsidiaries, which are venture capital businesses. Small and medium-sized enterprises are weak in both financial and human resources, and their main task is to stay in the emerging market infrastructure. The general patterns of innovation are 
seen here: despite the relatively large resource opportunities to revitalize innovation in large enterprises, the economic impact of innovation in all enterprises is roughly the same.

In order to properly assess the feasibility of stimulating SME or supporting large business venture capital funds, it is necessary to use primarily the comparative analysis of existing businesses in part:

- the risk level of innovative enterprise projects;

- time for projects to be implemented and profit edited in the near or more distant future;

- the scale and importance of innovation-solving tasks at the state, regional and corporate levels of governance.

The industrial cluster is becoming increasingly important to promote the competitive advantages of industries. Based on an analysis of the economic structure of the Kemerovo region, the following sectors promising to support and form clusters were identified (table 1).

Table 1. Key propulsive sectors analysis - Kemerovo region. Source: composed by the authors

\begin{tabular}{|c|c|c|c|c|c|}
\hline Industry sectors & $\begin{array}{l}\text { Backward } \\
\text { linkages }\end{array}$ & Exports & Employment & $\begin{array}{l}\text { Value } \\
\text { added }\end{array}$ & Total \\
\hline $\begin{array}{ll}\text { Agriculture } & \text { forestry } \\
\text { fishing } & \\
\end{array}$ & & $\checkmark$ & & & \\
\hline Mining & $\checkmark$ & $\checkmark$ & $\checkmark$ & $\checkmark$ & 4 \\
\hline Manufacturing & $\checkmark$ & $\checkmark$ & $\checkmark$ & $\checkmark$ & 4 \\
\hline $\begin{array}{l}\text { Electricity, gas and water } \\
\text { supply }\end{array}$ & $\checkmark$ & & & & \\
\hline Construction & $\checkmark$ & & $\checkmark$ & $\checkmark$ & 3 \\
\hline Wholesale trade & & & & $\checkmark$ & 1 \\
\hline Retail trade & & & & $\checkmark$ & 1 \\
\hline $\begin{array}{l}\text { Accommodation, cafes, } \\
\text { restaurants }\end{array}$ & & & & $\checkmark$ & 1 \\
\hline Transport and storage & $\checkmark$ & & $\checkmark$ & $\checkmark$ & 3 \\
\hline Communication services & $\checkmark$ & & & $\checkmark$ & 2 \\
\hline Finance and insurance & $\checkmark$ & & & & 1 \\
\hline $\begin{array}{l}\text { Property and business } \\
\text { services }\end{array}$ & & & & & 0 \\
\hline $\begin{array}{l}\text { Government } \\
\text { administration \& defence }\end{array}$ & & & & & 0 \\
\hline Education & $\checkmark$ & & $\checkmark$ & & 2 \\
\hline $\begin{array}{l}\text { Health and community } \\
\text { services }\end{array}$ & $\checkmark$ & & & $\checkmark$ & 2 \\
\hline $\begin{array}{l}\text { Cultural and recreational } \\
\text { services }\end{array}$ & $\checkmark$ & & $\checkmark$ & & 2 \\
\hline $\begin{array}{l}\begin{array}{l}\text { Personal and } \\
\text { services }\end{array} \\
\end{array}$ & & & $\checkmark$ & $\checkmark$ & 2 \\
\hline
\end{tabular}

Table 1 shows that it is advisable to combine coal mining, steel, transport and wholesale in a single cluster that will allow the production of varieties of any quality and form. The cluster should include research universities, the development of which can be used to set up lines for the production of pipes from new materials, which is important for the oil and gas industry of Russia, large deposits are located in the neighboring Krasnoyarsk region and then possible transportation on the internal rivers. 
Establishing effective links between these participants will create a cluster that provides products throughout the country, with the possibility of export. Moving to an innovative environment requires creating a creative environment capable of generating new knowledge to put it into practice in the industrial sector through an interaction of internal and external organizational factors. The effect of these activities will be continuous competitiveness (fig.4), improved product quality and progress in related areas [16].

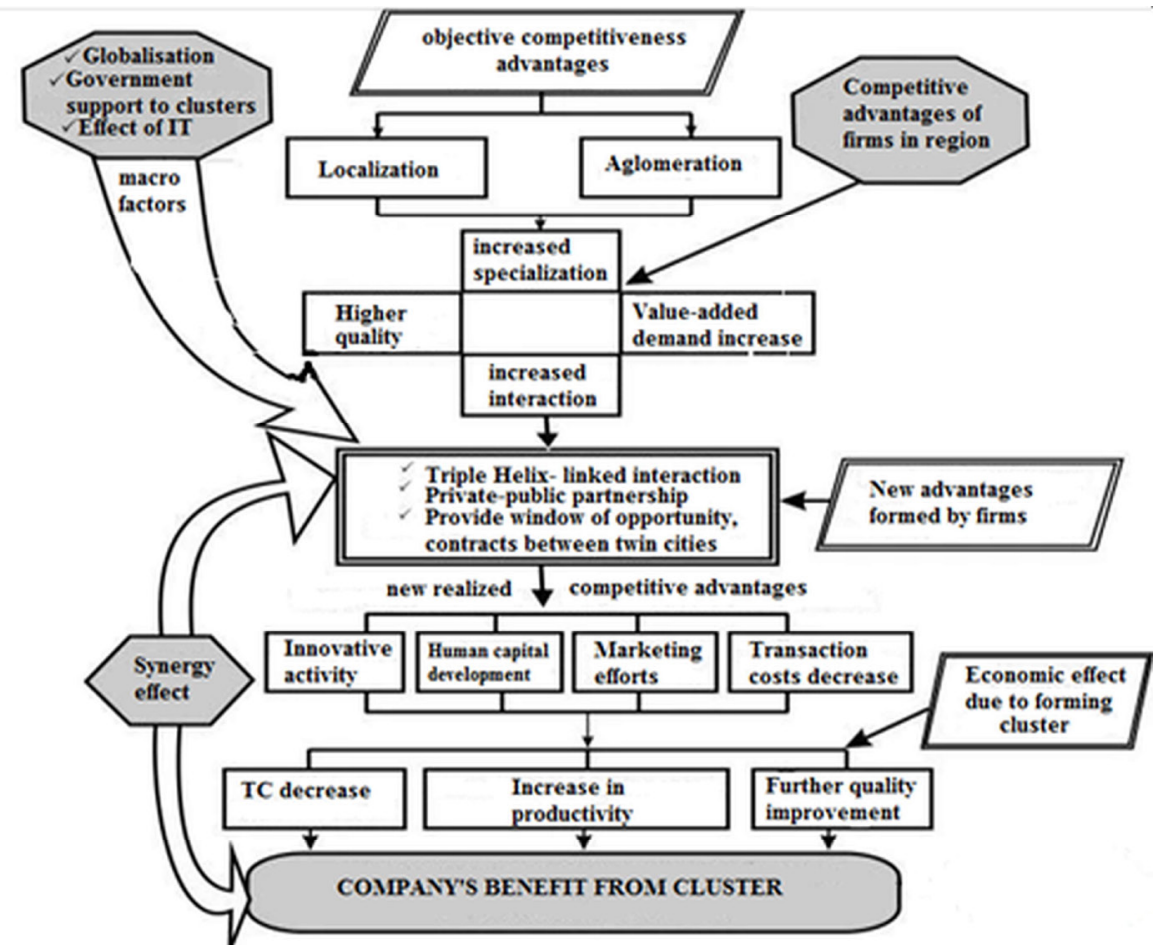

Fig. 4. Cluster competitiveness model Source: composed by the authors.

The availability of support infrastructure is a prerequisite for any industrialization to continue for a long time. A reliable road network provides input flows and knowledge and innovation between actors [17].

Diversifying the economy allows it to be resistant to crises. In this regard, it is necessary to develop not only the mining industry using the cluster approach, but also other industries. One of the promising areas of economic development in the Kemerovo region may be tourism. Tourist clusters rely on natural resources and other material resources, and legends and other intangible resources to transform intangible culture into specific products and create an atmosphere of travel with experience oriented to this function. The plan for the development of tourism clusters should involve the planning of local urban and rural construction and land use. The leap in the development of the tourism industry should be determined by strengthening the integration of tourist resources and facilities, intensifying efforts to promote the cluster development of tourist attractions and tourist enterprises, as well as the creation of tourist brands with basic competitiveness and great influence [18].

The cultural tourism industry has been developing rapidly lately, but due to the specifics of the tourism industry, the competitiveness of cultural tourism in industrial regions depends on many factors. Based on the analysis of the development of clusters in Hubei Province, it can be concluded that cultural and environmental tourism makes it possible to implement major projects, contributes to the emergence of new investment zones [18]. 
In addition to traditional scenic facilities and hotels, additional infrastructure is needed:

- theme parks;

- tourist shops;

- sports and wellness facilities; rural tourist property;

- museums and objects of popular culture;

- rehabilitation facilities and educational activities to study the flora and fauna of the territories, survival in the forest, etc.

Tourism projects encourage investment in food, housing, transport, tourism, shopping and entertainment and other areas of tourist areas. At the same time, according to statistics of the Kemerovo region, as of 2019, most of the facilities are located in major cities, the region has about 30 local travel agencies, recreation facilities and reserves have about 1-2 hotels for 200 beds.

The tourism cluster should consider tourism as a leading factor and demand for tourism services as a driving force. Creating and promoting a regional brand: major scenic locations, tourist services, small tourist towns, a central tourist town, and rural idyllic landscapes (core scenic spots, tourist service base, small tourism towns, central tourism city, and rural idyllic scenery) to tourism enterprises in the cluster to reduce operating costs or generate additional income. And the regional authorities will receive additional revenues and will be able to increase production efficiency by focusing on a certain part of the production value chain.

\section{Conclusion}

Because the economy of consumption leads to wasteful and not always productive use of resources, the industrial development model, oriented to one market/product type, is ineffective and gives way to a cluster-based development model [19].

In order to improve the efficiency of clusters, the interplay between enterprises and institutions of regional systems is needed. The key resource is social networks, which are a form of spatial economic organization, standing between the market and the hierarchy of the company.

The development of the cluster is limited by the needs of the market, but the continuity of the cluster is achieved by the transition to an innovative environment. The creation and promotion of regional innovation systems is designed to raise awareness of innovative systems and innovative practices of companies and enables regional development professionals to reformulate issues and opportunities that go beyond current socio-economic factors, development paradigms and planning horizons, taking into account a wider range of regional development opportunities. While it creates the opportunity to "plan innovation" by raising awareness of innovation, to support and develop regional innovation systems and innovate will help diversify the economy, the universal recipe is the development of the tourism industry.

Compared to traditional industries, the cultural tourism industry is a relatively new area. It combines tourism with the intention of creating strong links between regional enterprises and achieving twin cities. It is an effective form for economies of scale and agglomeration economies, and towards a social, cultural, environmental and managerial environment.

\section{References}

1. Q. Luhui, IOP Conf. Ser.: Earth Environ., Sci. 267, 062032 (2019)

2. X. Xiang, W.-Ch. Huang, Sustainability, 11, 6725 (2019)

3. Federal state statistics service (Rosstat, Moscow, 2019)

4. E. Shavina, S. Fisunov, E3S Web Conf., 105, 04018 (2019) 
5. Ö. Karakayaci, İ. Dinçer, MEGARON, 13(3), 374-394 (2018)

6. A. Gunadi, Munich Personal Repec Archive Paper, 1, 28032 (2011)

7. M. C. Chen, Industrial district and social capital in Taiwan's economic development: An economic sociological study on Taiwan's bicycle industry. (Yale University, Yale, 2002)

8. A. Isaksen, F.T ödtling, M. Trippl, Theoretical Advances, Empirical Cases and Policy Lessons, 10, 221-238 (2018)

9. D. L. Birch, Job Creation America. How Our Smallest Companies Put the Most People to Work (Free press, New York, 1987)

10. D. Birch, J. Medoff, Gazelles (Westview, Boulder, 1994)

11. M. G. Bosco, European Planning Studies, Vol. 15, 8, 1085-1111 (2007)

12. S. Kinnear, I. Ogden, Resources Policy, 39, 42-53 (2014)

13. O.A. Fokina, Logos et Praxis, 4 (34), 11-15 (2016)

14. N. Evans, J. Sawyer, Australas. J. Reg. Stud., 15 (3), 355-372 (2009)

15. V. Petkova-Timmer, S. Lockie, J. Rolfe, G. Ivanova, Rural Soc., 19 (3), 211-228. (2009)

16. O. Kalenov, S. Kukushkin, R. Kamanina, E3S Web Conf., 105, 04028 (2019)

17. S. Kukushkin, O.Kalenov, E3S Web Conf., 105, 04022 (2019)

18. A. Otamisa, N. Yuzbasionlu, Procedia-Social and Behavioral Sciences, 99, 682-690 (2013)

19. O. Kalenov, E. Shavina, E3S Web Conf., 41, 04054 (2018) 